\title{
Physical Development Framework for Climate Change Adaptation in Malaysian Construction Industry - Current Scenario and Way to Improve
}

\author{
MOHD NOR RASHIDI ${ }^{*}$, RAWSHAN ARA BEGUM ${ }^{2}$, \\ MAZLIN BIN MOKHTAR ${ }^{1}$ and JOY JACQUELINE PEREIRA ${ }^{1}$
}

\author{
${ }^{1}$ Institute for Environment and Development (LESTARI), \\ National University of Malaysia, Bangi 43600, Kajang, Selangor D. E., Malaysia. \\ ${ }^{2}$ Institute of Climate Change, National University of Malaysia, \\ Bangi 43600, Kajang, Selangor D. E., Malaysia. \\ http://dx.doi.org/10.12944/CWE.9.3.01
}

(Received: November 11, 2014; Accepted: November 24, 2014)

\begin{abstract}
Climate change has been universally recognized as a global problem. The emissions are increasing rapidly with the growth of economy especially in developing country. The vulnerability of infrastructures and built environment due to climate change will extend to the whole region, if no proper and immediate actions being outlined and implemented at the very early stage in the development cycle. Implications of the changes in climate predicted in Malaysia mean that present road, infrastructure and building that have been well developed at current and before, may not be suitable and equipped to withstand with the changes in the climate. The impact may cause defect to the structures, and the construction activity itself may become more difficult to implement due to hot and dry weather, and more frequent precipitation and heavy storms. The inclusion of the perspective of socio-technical systems shall provide any possibilities for a much better system and right approach in adapting to the change of climate. Due to that, this study will explore on how the issue of climate change together with the involvement of multidisciplinary experts can be integrated into the physical development framework particularly for decision making process during the stage of planning of the construction cycle, and how it would impact the current scenario particularly in Malaysia.
\end{abstract}

Key words: Climate change impact, Adaptation, Physical construction cycle.

\section{INTRODUCTION}

Nowadays, climate change has been universally recognized as a global problem. The emissions are increasing rapidly and in tandem with the growth of economy especially in the developing country. Climate change and sustainable development have been addressed separately in both research and policy (VijayaVenkataRaman et al., 2012) nevertheless, there are strong linkages between the two, and the relationship is an emerging issue regionally and globally. It involved a broad range of issues involving the development matters, social state and environmental dimensions.
Infrastructure is an important component of human settlement which facilitates the activities of the human population (Stewart et al., 2011). The vulnerability of infrastructures and built environment due to climate change will extend to the whole region, if no proper and immediate actions being outlined and implemented at the very early stage. In Malaysian scenario for example, the potential indirect effects of climate change will include loss of economical, ecological and other values due to the loss of land and coastal habitats, and increased flood risk to the people, land and infrastructures. Implications of the changes in climate predicted in Malaysia mean that present infrastructure and building that have been 
well developed at current and before, may not be suitable and equipped to withstand with the changes in the climate. The impact may cause cracking and deterioration of concrete walls and structure failures to the impacted buildings and infrastructure (Stewart et al., 2011). Concreting activity may become more difficult in hot and dry weather, and more frequent precipitation and heavy storms will also cause the mould growth problems to the finished structures. The perspective of socio-technical systems shall provide any possibilities and opportunities for describing the much better system and exploring the right approach or adapting it to the impact generated by the change of climate (Chappin \& van der Lei, 2014). Due to that, this study will explore on how the issue of climate change together with the involvement of multidisciplinary experts can be integrated into the physical development framework for decision making process during the stage of planning of the construction cycle and how it would impact the current scenario particularly in Malaysia. A comprehensive study in this regard had been previously conducted by Mills et al. (2009) which proposed a general framework for the consideration of climate impacts on the field of transportation.

\section{The Consequences of Climate Change}

The increasing emissions of greenhouse gases (GHG) from various industries and activities has led to climate changes including the phenomena known as 'global warming' (VijayaVenkataRaman et al., 2012). In Asia the impact of the events can be clearly seen; increased flooding in Malaysia and lengthy droughts in Australia, while in Europe, there are events such as increasingly intense summer heat waves and melting glaciers (Yau \& Hasbi, 2013). The impact of climate change are wide ranging (Alló \& Loureiro, 2014) involving the environment and human health (United Nations Framework Convention, 2012). The abrupt change in which the arctic has undergone for quite some time during the past decade involved the atmospheric sea-level pressure, ice cover, change in the pattern for precipitation (Zhou et al., 2012), change in hydrology and also change in water mass distribution (VijayaVenkataRaman et al., 2012). Due to these consequences which also involve the aspect of social and economy, a large number of policies have been developed globally aimed at reducing the impact. The most significant international agreement was the
Kyoto Protocol, which came into effect in year 2005 (Alló \& Loureiro, 2014). In relation to the construction sector, the consequences may also pose a threat to the existing and future infrastructure (Schweikert et al., 2014; Van Vliet et al., 2012). Considering the nature of the consequences from the climate change impact, adaptation (anticipating and responding to the impacts of climate change) may be crucial (Schweikert et al., 2014) as the mitigation may prove insufficient to safeguard the infrastructures especially in the future (Chappin \& van der Lei, 2014).

\section{The Existing Scenario in Malaysia}

Malaysia is experiencing an encouraging socio economic development especially in its quest towards Vision 2020 championed by its prominent leaders. The success can be attributed to the Government's efforts and commitments in developing physical projects which includes constructions of new townships and public infrastructures such as airports, dams, ports, roads, hospitals and schools. Although in reality the construction industry itself does not contribute or emit greatly to GHG emissions, Malaysian Government however does not ignore the GHG emissions from individual construction firm and has issued a challenge to the developer or construction players to take some approach to not only reducing emissions from their equipments and development activities, but also to reduce other type of pollutants that might have directly and indirectly emitted, which could contribute to the impact of climate change.

In fulfilling the development both physically and economically, the Government of Malaysia has put forth various efforts for the full implementation and completion of its development blueprint under the five-year Malaysian Plan (MP). Public Work Department (PWD) as the Government's main implementing agency has been given the full authority and responsibility to implement all the well-planned physical projects and also in managing the environment aspect especially those in the construction phase which are of paramount importance to be given serious attentions. How the development comes with a high price to the environment. Even though there are several initiatives to manage and solve environmental problems at construction sites, the best solution to 
overcome the issue and mitigate the environmental pollution from construction activities has yet to be found (Rashidi et al., 2014). The physical developments which include the constructions of roads and highway infrastructures, and building are found to have detrimental effects, especially towards water and air quality (Public Work Department, 2012). Through implementation of environmental management plan (EMP); surveillance activities for water, air and noise are being conducted. Based on the observation of the surveillance results for several audited projects, some did not conform to the limit set by the environmental requirements or the corporate target outlined by the department policy. According to the statistics of year 2012 for several development projects that involved the infrastructures and buildings projects, there were non-conformances (NCRs) found for some environment parameter such as total suspended solids (TSS) and turbidity for as water quality which exceeded the requirements set by the agency (Public Work Department, 2012). Based on the report on environmental audit, there were also several NCRs found on sites, which if not mitigated at the early stage will aggravate the pollution impacts of the construction activities to the surrounding area.
A very good example was the occurrence of slope erosion at Cameron Highlands in year 2006. Due to the heavy rainfall, the slope eroded tremendously that caused the mud and eroded soil entering the existing roads and downstream river. In real situation, the surface running water from the erosion occurred will indirectly alleviate the suspended solids in the water body and river streams. This will cause shallow riverbed which indirectly caused the flash flood in some areas due to the heavy downfall.

In Malaysia, there has been an increasing temperature trend for the past 40 years (Yau \& Hasbi, 2013). According to the climate simulations, that have been studied using twelve coupled AtmosphereOcean General Circulation Models (AOGCMs), an ensemble mean for temperature and rainfall was obtained using nine out of twelve AOGCMs which were based upon the A1B scenario (NAHRIM \& DID, 2009). The result shows an increasing temperature trend for the Peninsular of Malaysia, Sabah and Sarawak. The projected temperature increase among the nine AOGCMs for East Malaysia and Peninsular Malaysia are 1.0 degrees Celsius to 3.5 degrees Celsius, and 1.1 degrees Celsius to

(a)

(b)

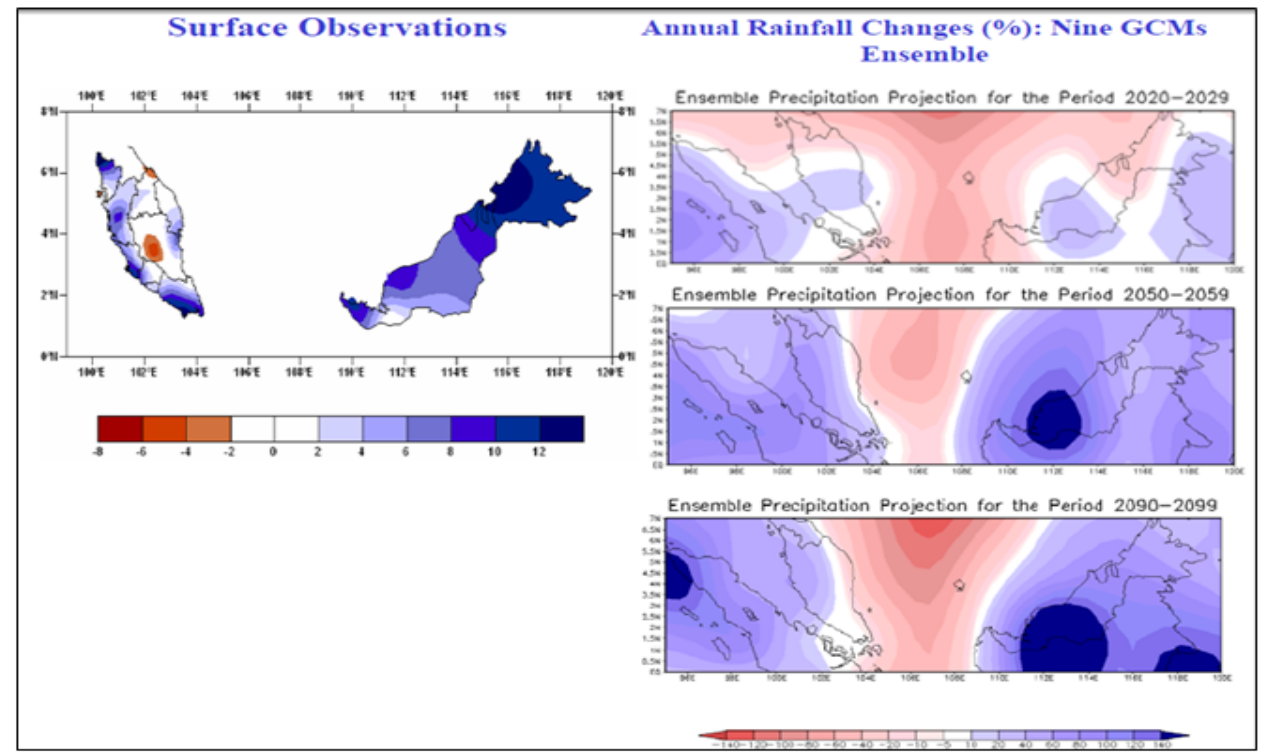

Fig. 1: Comparison of Annual Rainfall Change (\%): (a) For The Period 2000 - 2007 Relative To The Period 1990-1999 (Last Decade of the 20th Century), based on the MMD's Surface Observation Stations Data; and (b) for The Periods 2020-2029, 2050-2059, and 2090-2099 Relative To The Period 1990-1999 based on the Nine AOGCM Ensemble. Source: Malaysian Meteorological Department Scientific Report, 2009 
3.6 degrees Celsius respectively. Rainfall over the western Peninsular of Malaysia is projected to increase while there is a reduction projected for eastern Peninsular of Malaysia (see Figure 1 and Figure 2). For East Malaysia, the AOGCMs models have projected the rainfall over western Sarawak to increase significantly by the end of the 21 st century (NAHRIM \& DID, 2009). The circulation of Northeast Monsoon during month of December, January and February for the region of Asia was also analyzed using the 9 AOGCMs (NAHRIM \& DID, 2009) where most of the major flood projected to occur in Malaysia during this period. This issue had been highlighted in PWD Management Review year 2007, in which the community of Sungai Buloh area in Selangor had complained the issues of flash flood nearby their housing area. This is part of the complaints by the public on the pollution generated by the physical development projects nearby their residential areas which had been raised during the review.

As for the present time, few studies and research have focused on the possible impact of climate change on the construction sectors. The future changes scenario such as level of precipitation, the temperature and frequency of extreme weather events should be reviewed nowadays and to be taken into considerations during the planning and pre-construction stage of physical development projects. The staging or duration within a calendar year of the respective development project is also an important aspect to be taken into consideration due to the climate factors that are unpredictable nowadays. Based on the previous environmental quality monitoring for selected road and building development projects, the permissible emission level from the construction industries need to be reviewed as to adapt to the current scenario of weather. As for the building sector, the typical life span of a building is approximately ranging from around 60 to more than 100 years. Due to that, the implications of different climate change scenarios should be considered on buildings structure in advance which will enable the society to adapt to these changes in the future (Yau \& Hasbi, 2013).

The efforts to address climate change are also shifting from strategies for mitigation to a new emphasis on adaptation (Said Irandoust, 2009). Although there were thrusts on energy efficiency and promotion of renewable energy sources, construction companies need to demonstrate that they are reducing their own carbon impacts, as well as working in partnerships and tandem with other stakeholders on adapting to climate change. However, these are not happening in the existing framework for physical development in relation to construction matters in Malaysia. The pathway to enhancement of sustainability should not only involve the respective ministry or client (government agency), developers or contractors and the technical experts among the practitioners, but it should also involve other important and different background of academician, economist or even the leader of

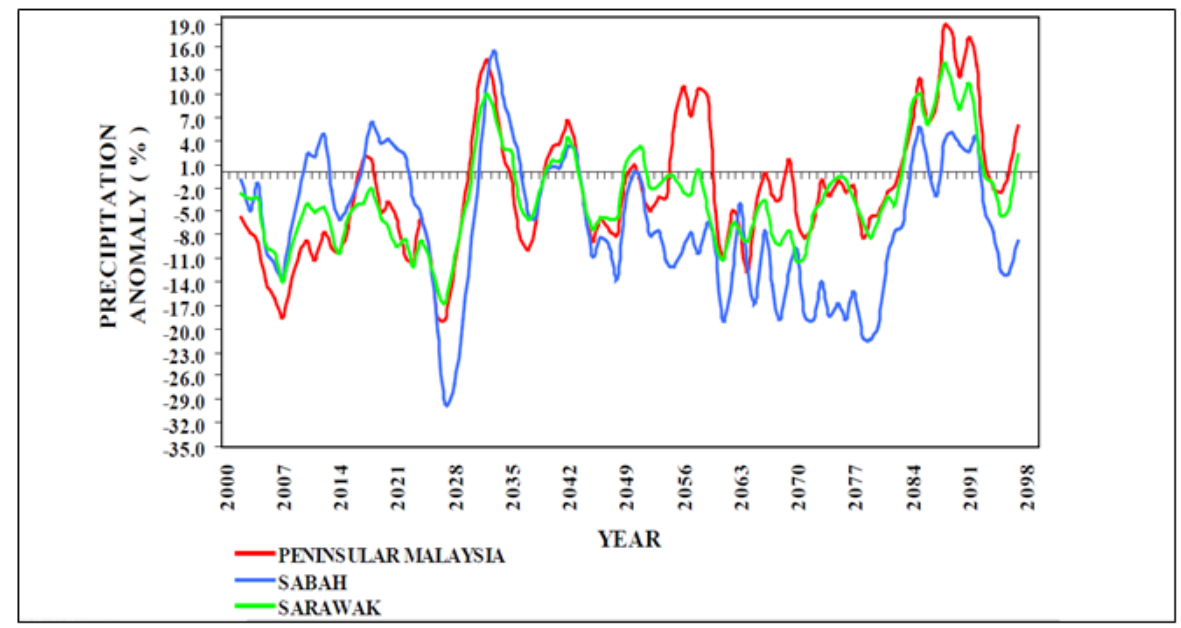

Fig. 2: Annual Rainfall Anomaly driven by HadCM3 A1B Source: Malaysian Meteorological Department Scientific Report, 2009 
society. The existing framework which is being adopted nowadays in the construction cycles is as shown in Figure 3.

The industrial players, relevant authorities and the technical experts have to work out new linkages among the stakeholders, and instil greater cooperation and responsibility in helping the people and industries to cope with the effects and impacts of the climate change. The increment of maintenance and repairing cost of the existing infrastructure for example is also a good indicator that an improved and revised technical specification and design frameworks should be well-in placed to adapt the change of the climate. Hence, it is of paramount essential that the elements of climate change adaptations to be considered in the development framework for any construction projects and also in the decision-making process among the stakeholders. The development frameworks employed need to be ensured, having the capacity and capability to endure in the continuous changing climate.

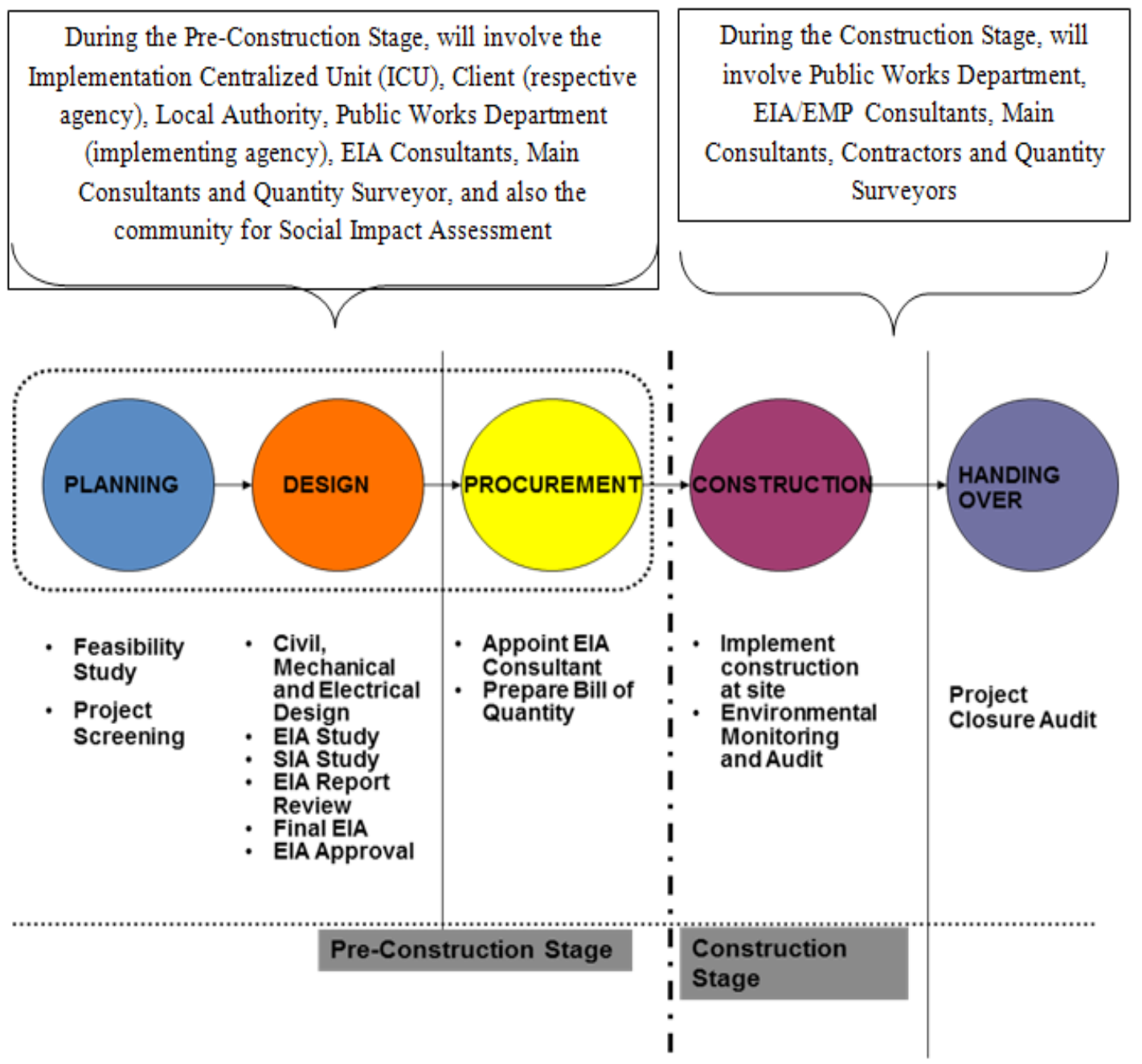

Fig. 3: The Existing Framework for Physical Development in Construction Cycle 


\section{How It Can Be Improved?}

The existing framework for implementing a physical construction project is still an important basis and reference for the purpose of improvement and recommendations of a new one. All the loopholes and weaknesses need to be filled up and improved. Since the subjects of climate change adaptation comprises three main subjects; the management, science and engineering, hence this new developed framework shall encompass and emphasize on the involvements and incorporation of multi-disciplinary experts during the planning stage of a physical development. These shall involve an establishment of steering committee (SC) and several working groups (WG) that are inter-related to each other. In this new set-up framework, several government agencies and technical experts will be brought in, to add in a new dimension to the existing one. As the policy makers need insight into the causalities both in the technical and the social domains (Chappin \& van der Lei, 2014), hence this new framework shall need the expertise and consultation from the technical experts such from Department of Irrigation and Drainage (DID) and the professionals from Institute

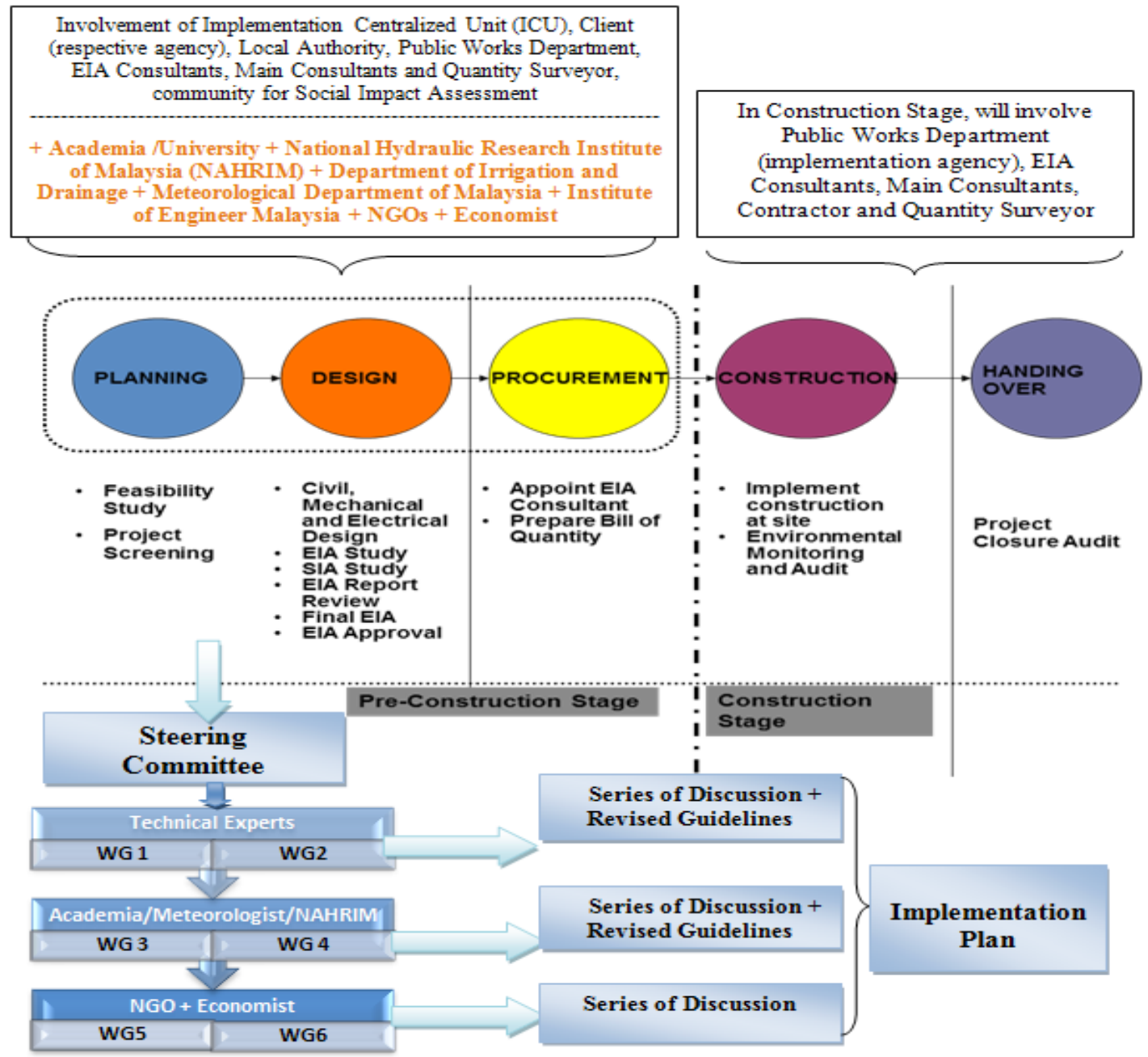

Fig. 4: The Newly Proposed Frameworks for Physical Development in Adapting to Climate Change Impact in Construction Cycle 
of Engineer Malaysia (IEM). They will form a working group of WG1 and WG2, in which through a series of discussions under this committee, a new revised design guideline and technical specification that taking into account and consideration, the adaptation and mitigation measures shall be produced. The same goes to the other working group namely WG3 and WG4 that comprise of the academicians and researchers from the university such as Institute for Environment and Development (LESTARI) of National University of Malaysia, Malaya University and several other academia from other higher educational institutions; together with the experts from the National Hydraulic Research Institute of Malaysia (NAHRIM) and Meteorological Department of Malaysia. The last two groups will be WG5 and WG6 that will include the non-government agency (NGO) and the economic experts. They will also sit together discussing the issue of climate change, socio-economical impacts to the community and outlining the best possible implementation that taking into consideration the welfare and benefit of the communities. These six working groups which are driven by a steering committee will also sit together and brainstorming their group's outcomes, finding the consensus and outlining the best implementation plan that take into account the societal, economical and environmental aspects. As the pathway towards the sustainable development requires not only the aspects of society, economy and environment, hence an integration of multi-disciplinary theme shall provide a better platform for the establishment of new physical development framework. It is of paramount important to develop and implement sustainable development frameworks and policies at various level, to generate a new generation of policymakers and planners who will be able to prepare and implement sustainable development policies, and also the engineers or scientists coming from various background who are able to invent, develop, improve and disseminate a more environmental friendly technologies. Higher learning institutions also have an important role in development efforts, especially in addressing emerging issues such as climate change and disaster mitigation (Said Irandoust, 2009). The key components during the development process must entail interaction between the research and education, the practical implementation on the field, the feedback into the academic system and also the consecutive flow of information between the actors involving all levels (Said Irandoust, 2009). The academia nowadays has the important roles to interconnect the linkages between the public and private sectors, and also has important tasks to facilitate any transfer of technology. It is critical to incorporate the role of academia into the frameworks for embedding sustainability into the development process and instilling the concept towards the industrial practitioners. The newly proposed framework will be having the outputs that consist of revised design guidelines and specifications that incorporate elements of mitigation and adaptation to the climate change. These outcomes will be reviewed by the proposed multi-disciplinary experts from different fields that being brought into the picture of new development framework. This so called long term adaptation strategies might not have an instant impact to the nation; however the implementation of the frameworks will ensure the safeguards of the future generations without disregarding the current need of community.

With this new proposed development framework, it will provide a basis to review, improve and revise the existing technical guidelines and aspect of design of the construction of road, building and other infrastructure. The implications of the continuous and unpredicted changes of Malaysia's climate mean that the present building and infrastructure may not be well-equipped and suited to withstand and cope with the changes. Some risks that are associated with the unpredicted climate change consist of slope instability, mould problem, wind loading that could cause failure of structures, less durability of concrete that due to extreme hot and increase in temperature, and also delay in the progress of construction programme that will cause difficulty in projecting the works programme of a construction project. In fact, some elements under the ISO 14001 of Environmental Management System for the construction industry will also require some changes and amendments for the purpose of sustainability that taking into consideration the adaptation of climate change impacts. For instance, there is an urgent need to review the current permissible emission level of the construction sector that will go parallel with the policy and regulations which being outlined by the Department of Environment Malaysia (DOE). Furthermore, there would be also a few of innovations and changes in 
relation to environmental auditing elements under the management systems to suit and fulfil the current needs and scenario.

This would be a great opportunity for the Government of Malaysia to review their current policy to ensure that the New Economic Model (NEM) and the Government Transformation Plan (GTP) as being announced by the Prime Minister of Malaysia to achieve a high income nation without neglecting other important aspects such as environment and social could be achieved with success. The voice of the community is the best indicator to indicate that the new physical development framework and the implementation of the NEM are going parallel and compensate each other. It is important to emphasize that development agendas and modernization of a country should go parallel, without compromising any destructions to the environment and neglecting the need of the social.

\section{CONCLUSIONS}

This study attempts to develop a new physical development framework for the purpose of adapting to climate change impact in the construction industry. From the framework, a new linkage among the stakeholder will be put in to improve and incorporate various technical discipline and expert. The experts from the sector of engineering, meteorology, hydrology, economy and social will be brought into the framework, to assist the ministry and government authority in the current framework. This shall ease the difficulty among the stakeholders particularly during the decision making process, as a diverse of input, ideas and opinion from several different experts will be taken into considerations. A more reliable, wiser and accurate decision making shall be produced hence will benefit all related parties especially the community and the surrounding natural environment. Indirectly, the newly proposed framework could be implemented effectively and achieve its mission in dealing with frequent environmental degradation issues due to or related to climate change impacts. With the use of right indicators, continual improvements of the frameworks shall be implemented and this will surely give positive benefits mainly to the community.

\section{ACKNOWLEDGEMENTS}

The author would like to thank Prof. Joy Jacqueline Pereira, Prof. Dr Mazlin bin Mokhtar and Assoc. Prof. Dr. Rawshan Ara Begum for reading and commenting the earlier version of this paper. The author also acknowledges the support and ûnancial support provided by the ZAMALAH LESTARI of the Institute for Environment and Development (LESTARI) and DPP-2014-105 Disaster and Climate Extreme of Universiti Kebangsaan Malaysia for realizing this study.

\section{REFERENCES}

1. Alló, M., \& Loureiro, M. L. The Role of Social Norms on Preferences Towards Climate Change Policies: A Meta-Analysis, Energy Policy, 73: 563-574 (2014)

2. Chappin, E. J. L., \& van der Lei, T., Adaptation of Interconnected Infrastructures to Climate Change: A Socio-Technical Systems Perspective. Utilities Policy, 31: 10-17 (2014)

3. Malaysian Meteorological Department, Scientific Report (2009)

4. Mills, B., Tighe, S., Andrey, J., Smith, J., and Huen, K., Climate Change Implications for Flexible Pavement Design and Performance in
Southern Canada', Journal of Transportation Engineering, 135(10): 773-782 (2009)

5. NAHRIM and Department of Irrigation and Drainage (DID): National Coastal Vulnerability Index Study - Phase 1 (2009)

6. Public Work Department, A Practical Guide for Environmental Protection and Enhancement Work : Technical Notes (Road) 16/03 (2006)

7. Public Work Department, Laporan Kajian Semula Pengurusan (KSP): Mesyuarat Kajian Semula Pengurusan Sistem Pengurusan Alam Sekitar, Kuala Lumpur (2012)

8. Public Work Department, Laporan Kajian Semula Pengurusan (KSP): Mesyuarat Kajian 
Semula Pengurusan Sistem Pengurusan Alam Sekitar, Kuala Lumpur (2007)

9. Rashidi, M. N., Begum, R. A., Mokhtar, M., \& Jacqueline, J., Criteria towards Achieving Sustainable Construction Through Implementation of Environmental Management Plan (EMP). Advanced Review on Scientific Research, 1(1): 43-64 (2014)

10. Said Irandoust, Sustainable Development in the Context of Climate Change, Springer Publication (2009)

11. Schweikert, A., Chinowsky, P., Espinet, X., \& Tarbert, M., Climate Change and Infrastructure Impacts: Comparing the Impact on Roads in ten Countries through 2100. Procedia Engineering, 78: 306-316 (2014)

12. Stewart, M. G., Wang, X., \& Nguyen, M. N., Climate Change Impact and Risks of Concrete Infrastructure Deterioration. Engineering Structures, 33(4): 1326-1337 (2011)

13. VijayaVenkataRaman, S., Iniyan, S., \& Goic, R., A Review of Climate Change, Mitigation and Adaptation. Renewable and Sustainable Energy Reviews, 16(1): 878-897 (2012)

14. Yau, Y. H., \& Hasbi, S., A Review of Climate Change Impacts on Commercial Buildings and Their Technical Services In the Tropics. Renewable and Sustainable Energy Reviews, 18: 430-441 (2013)

15. Zhou, Q., Mikkelsen, P. S., Halsnæs, K., \& Arnbjerg-Nielsen, K., Framework for Economic Pluvial Flood Risk Assessment Considering Climate Change Effects and Adaptation Benefits. Journal of Hydrology, 414-415: 539-549 (2012). 